\title{
LITERATURE REVIEW : EFEKTIFITAS PELVIC ROCKING EXERCISE MENGGUNAKAN BIRTHING BALL TERHADAP KEMAJUAN PERSALINAN PADA IBU PRIMIPARA
}

\author{
Lea Ingne Reffita ${ }^{1}$, Senditya Indah Mayasari ${ }^{2}$, Ummi Halfida $^{3}$, Wili Sinarti ${ }^{4}$, Yaumil Fitriyah $^{5}$, Zidni \\ Karimatun Nisa ${ }^{6}$ \\ Fakultas Ilmu Kesehatan Universitas Ibrahimy ${ }^{1}$, STIKES Widyagama Husada Malang ${ }^{2}$ \\ Fakultas Ilmu Kesehatan Universitas Ibrahimy ${ }^{3456}$ \\ e-mail: ${ }^{1}$ leaingne25@gmail.com, ${ }^{2}$ senditya.ap@gmail.com
}

\begin{abstract}
Indonesia's Health Profile in 2019 in general, there was a decrease in maternal mortality during the period 19912015 from 390 to 305 per 100,000 live births, if it is associated with the 2015 Millennium Development Goals $(M D G s)$, namely reducing the maternal mortality rate (MMR) to 102/100,000 live births. the maternal mortality rate did not reach the MDGs target. Physiological efforts are made to prevent prolonged labor, such as pelvic rocking exercise using the birthing ball technique. This is also a method that really helps respond to pain in an active way and reduces the length of the first stage of labor in the active phase. This study aims to determine the effectiveness of the implementation of pelvic rocking with a birthing ball on the progress of labor in primiparous women in 2020. This study uses Systematic Literature Reviews (SLR), which is a synthesis of systematic, clear, comprehensive literature studies, by identifying, analyzing, evaluating through the collection of existing data with an explicit search method and involving a critical review process in the selection of studies. In 6 journals, all journals perform pelvic rocking exercise techniques using the birthing ball technique when the mother enters the first stage of the active phase. The conclusion in this study is that all journals reviewed by researchers can be ascertained that all of these journals get the same results, namely stating that using the Pelvic Rocking Exercise technique with the help of a birthing ball can make delivery times for mothers go faster.
\end{abstract}

Keywords: Pelvic Rocking Exercise; birth balls; primipara; labor progress

\begin{abstract}
ABSTRAK
Profil Kesehatan Indonesia tahun 2019 secara umum terjadi penurunan kematian ibu selama periode 1991-2015 dari 390 menjadi 305 per 100.000 kelahiran hidup, jika dikaitkan dengan Millenium Development Goals (MDGs) 2015 yakni menurunkan angka kematian ibu (AKI) menjadi 102/100.000 kelahiran hidup maka angka kematian ibu tidak berhasil mencapai target MDGs. Upaya fisiologis yang dilakukan untuk mencegah persalinan lama, seperti pelvic rocking exercise dengan menggunakan teknik birthing ball. Hal ini juga merupakan salah satu metode yang sangat membantu merespon rasa sakit dengan cara aktif dan mengurangi lama persalinan kala I fase aktif. Penelitian ini bertujuan untuk mengetahui efektifitas pelaksanaan pelvic rocking dengan birthing ball terhadap kemajuan persalinan pada ibu bersalin primipara tahun 2020. Penelitian ini menggunakan Systematic Literature Reviews (SLR), yakni sebuah sintesis dari studi literatur yang bersifat sitematik, jelas, menyeluruh, dengan mengidentifikasi, menganalisis, mengevaluasi melalui pengumpulan data-data yang sudah ada dengan metode pencarian yang eksplisit dan melibatkan proses telaah kritis dalam pemilihan studi. Dalam 6 jurnal semua jurnal melakukan tehnik pelvic rocking exercise dengan menggunakan teknik birthing ball saat ibu memasuki kala I fase aktif. Kesimpulan dalam penelitian ini adalah semua jurnal yang peneliti review dapat dipastikan bahwa kesemua jurnal tersebut mendapatkan hasil yang sama yaitu menyatakan bahwa dengan menggunakan teknik Pelvic Rocking Exercise dengan bantuan alat birthing ball dapat membuat waktu persalinan pada ibu bersalin menjadi lebih cepat.
\end{abstract}

Kata kunci: Pelvic Rocking Exercise; birthing ball; primipara; kemajuan persalinan 



\section{PENDAHULUAN}

\section{Latar Belakang}

Persalinan adalah suatu proses alamiah dimana seorang wanita melahirkan bayi yang diawali dengan kontraksi uterus yang teratur dan memuncak pada saat pengeluaran bayi sampai dengan pengeluaran plasenta dan selaputnya dimana proses persalinan ini akan berlangsung selama 12 sampai 14 jam $^{(1)}$. Persalinan dikatakan normal apabila pengeluaran seluruh hasil konsepsi terjadi pada usia kehamilan 3742 minggu tanpa disertai dengan penyulit. Proses persalinan dimulai dari adanya kontraksi rahim yang menyebabkan adanya pembukaan serviks. Proses ini disebut dengan Kala I persalinan. ${ }^{(2)}$

Kala I persalinan diartikan sebagai permulaan kontraksi sejati yang dapat menyebabkan terjadinya pembukaan serviks dan diakhiri dengan pembukaan lengkap. Kala I persalinan terdiri dari kala I fase laten dan kala I fase aktif. Kala I fase laten adalah keadaan dimana pembukaan serviks berlangsung lambat hingga pembukaan $3 \mathrm{~cm}$ yang berlangsung selama 7-8 jam, sedangkan kala I fase aktif adalah keadaan dimana pembukaan serviks berlangsung mulai dari pembukaan $4 \mathrm{~cm}$ hingga $10 \mathrm{~cm}$ yang berlangsung selama 6 jam yang terdiri dari 2 jam periode akselerasi, 2 jam periode dilatasi maksimal dan 2 jam periode deselerasi. Fase ini ditemui pada primigravida. Sehingga normalnya lama kala I persalinan pada primigravida berlangsung selama13-14 jam sedangkan pada multigravida berlangsung selama 6-7 jam. ${ }^{(3)}$

Menurut informasi dari World Health Organization (WHO) tahun 2018 ditemukan 99\% kematian ibu terjadi di negara berkembang yaitu 239/100.000 kelahiran hidup, hal ini berbanding terbalik jika dibandingkan di negara maju yaitu $12 / 100.000$ kelahiran hidup. Sementara itu menurut Profil Kesehatan Indonesia tahun 2019 secara umum terjadi penurunan kematian ibu selama periode 19912015 dari 390 menjadi 305 per 100.000 kelahiran hidup, jika dikaitkan dengan Millenium Development Goals (MDGs) 2015 yakni menurunkan angka kematian ibu (AKI) menjadi 102/100.000 kelahiran hidup maka angka kematian ibu tidak berhasil mencapai target MDGs. Jumlah kematian ibu menurut provinsi tahun 2018-2019 terdapat penurunan dari 4.226 menjadi 4.221 kematian ibu di Indonesia berdasarkan laporan ${ }^{(4)}$

Berbagai upaya fisiologis dilakukan untuk mencegah persalinan lama, seperti senam hamil, teknik nafas dalam dan rebozo.Upaya lainnya dalam mencegah persalinan lama seperti pelvic rocking exercise dengan menggunakan teknik birthing ball yang mendukung persalinan agar dapat berjalan secara fisiologis. Hal ini juga merupakan salah satu metode yang sangat membantu merespon rasa sakit dengan cara aktif dan mengurangi lama persalinan kala I fase aktif ${ }^{(5)}$. Duduk lurus di atas bola maka gaya gravitasi bumi akan membantu janin atau bagian terendah janin untuk segera turun ke panggul sehingga didapatkan waktu persalinan lebih pendek atau singkat ${ }^{(5)}$.

Salah satu upaya untuk mempercepat proses persalinan yaitu menggunakan birthing ball. Pada saat ibu bersalin menggunakan birthing ball, posisi tubuh memungkinkan gravitasi mempercepat dilatasiserviks. Birthing Ball dapat membantu mempersingkat lama kala I fase aktif dimana ibu bersalin akan duduk diatas bola dengan gerakan memutar pinggul. Hal ini memungkinkan kepala bayi menekan leher rahim yang dapat mendorong dilatasi. ${ }^{(6)}$

\section{Tujuan Penelitian}

Tujuan dari penelitian ini adalah untuk mengetahui keefektifan tehnik pelvic rocking exercise menggunakan birthing ball terhadap kemajuan persalinan kala 1 fase aktif tahun 2021 melalui Systematic Literature Review

\section{METODE}

Penelitian ini merupakan penelitian dengan menggunakan metode studi kepustakaan atau literatur review. Literatur review merupakan ikhtisar komprehensif tentang penelitian yang sudah dilakukan mengenai topik yang spesifik untuk menunjukkan kepada pembaca apa yang sudah diketahui tentang topik tersebut dan apa yang belum diketahui, untuk mencari rasional dari penelitian yang sudah dilakukan atau untuk ide penelitian selanjutnya ${ }^{(7)}$. Studi literatur bisa didapat dari berbagai sumber baik jurnal, buku, dokumentasi, internet dan pustaka. Metode studi literature adalah serangkaian kegiatan yang berkenaan dengan metode pengumpulan data pustaka, membaca dan mencatat, serta mengelolah bahan penulisan. Jenis penulisan yang digunakan adalah studi literatur review yang berfokus pada hasil penulisan yang berkaitan dengan topik atau variabel penulisan. ${ }^{(8)}$

Data dalam penelitian ini adalah data sekunder. Data Skunder adalah data yang di peroleh secara tidak langsung. Dalam penelitian ini sumber yang di gunakan yaitu di peroleh dari text book dan jurnal ilmiah. Hasil pengumpulan data disajikan dalam bentuk Preferred Reporting Items for Systematic Reviews and Metanalyses (PRISMA) yang memuat artikel yang memenuhi kriteria inklusi dan ekslusi serta dapat diakui kredibilitasnya. Adapun kriteria inklusi dan ekslusi literatur yang akan di review yaitu: Kriteria Inklusi: jurnal diterbitkan dalam rentang waktu 5 tahun (2017-2021), tipe jurnal (research articles), menggunakan Bahasa Indonesia dan Bahasa Inggris, jenis penelitian kuantitatif, subjek penelitian primipara bersalin kala I fase aktif, dan berisi tentang efektifitas Pelvic Rocking Exercise menggunakan birthing ball atau efektifias dengan metode lain. Sedangkan kriteria ekslusi, antara lain: rentang waktu $>5$ tahun terakhir, tidak dapat diakses Full Text, tipe (literature review 
artikel), artikel tanpa sumber jurnal yang relevan/terduplikasi.

\section{HASIL}

Hasil seluruh literatur diseleksi dengan menggunakan kriteria inklusi dan eksklusi. Pencarian dan proses seleksi literatur dalam penelitian ini digambaran dalam bentuk Flow diagram Preferred Reporting Items for Systematic Reviews and Metaanalyses (PRISMA). Berdasarkan jurnal-jurnal yang telah dikumpulkan kemudian dianalisis kriteria kelayakan untuk digunakan dalam studi literature dalam penelitian, dan berdasarkan kriteria inklusi dan eksklusi, maka jurnal yang akan dijadikan acuan dalam membahas fenomena dan masalah adalah yang terkait dengan pelaksanaan pelvic rocking exercise menggunakan birthing ball pada ibu bersalin primipara.

Sejumlah 6 artikel yang terpilih menggunakan metode penelitian kuantitatif dengan desain penelitian quasy eksperimen sebanyak 4 artikel, pre eksperimen sebanyak 1 artikel, analitik observasional sebanyak 1 artikel.

\section{PEMBAHASAN}

A. Pelaksanaan pelvic rocking exercise dengan Birthing Ball dalam persalinan

Berdasarkan penelusuran artikel yang telah dilaksanakan terdapat 2 artikel yang menjelaskan tentang efektifitas Pelvic Rocking Exercise terhadap lama waktu persalinan pada ibu primipara.

Artikel pertama yaitu penelitian yang dilakukan oleh RR. Catur Leny Wulandari (9) tahun 2019 bahwa terdapat hubungan antara Pelvic Rocking Exercise dengan lama Kala I persalinan dengan hasil $\mathrm{p}$ value $0,008(<0,05)$. Penelitian ini membandingkan antara 2 kelompok yaitu 14 orang kelompok control dan 14 orang kelompok intervensi. Kelompok control tidak diberikan intervensi berupa Pelvic Rocking Exercise dengan birthball, sedangkan kelompok control melakukan proses persalinan biasa.

Hasil penelitian ini sependapat dengan artikel ke dua yaitu penelitian Diah Evawanna Anuhgera (10) tahun 2021 bahwa ada pengaruh terapi birth ball dengan teknik pelvic rocking terhadap lama persalinan pada kala I fase aktif dengan hasil mean difference 1.81 dan nilai $\mathrm{p}=0.001$. Penelitian ini membandingkan antara 2 kelompok yaitu 14 orang kelompok control dan 14 orang kelompok intervensi. Kelompok control tidak diberikan intervensi berupa Pelvic Rocking Exercise dengan birthball, sedangkan kelompok control melakukan proses persalinan biasa.

B. Pelvic Rocking Exercise menggunakan birthing ball terhadap kemajuan persalinan

Berdasarkan penelusuran artikel yang telah dilakukan terdapat 2 artikel yang menjelaskan tentang pengaruh dan hubungan teknik Pelvic
Rocking Exercise menggunakan birthing ball terhadap kemajuan persalinan

Artikel pertama yaitu penelitian yang dilakukan Ardina Batubara, Eva Mahayani dan Annisa Al FaiqAgma ${ }^{(11)}$ tahun 2019 bahwa dengan menggunakan uji-t sampel independen dimana nilai varians dianggap berbeda dan hipotesis alternatinya yaitu rata-rata kemajuan persalinan untuk status birth ball dilakukan dan tidak dilakukan adalah berbeda (two-tailed). Tingkat kepercayaan 95\% didapatkan nilai p-value 0,00001 < 0,05 yang berarti ada pengaruh yang bermakna antara Pelvic Rocking Exercise dengan birth ball terhadap kemajuan persalinan. Rata-rata kemajuan persalinan untuk status birth ball dilakukan dan tidak dilakukan adalah berbeda dimana status birth ball dilakukan lebih cepat 138,2 menit dibandingkan dengan status birth ball tidak dilakukan.

Hasil penelitian ini sependapat dengan artikel kedua yaitu penelitian Diah Evawanna Anuhgera, Nikmah Jalilah Ritonga, Riris Sitorus, Juni Mariati Simarmata (10) tahun 2021 bahwa terdapat 2 kelompok guna membandingkan yaitu kelompok control dan kelompok intervensi. Pada penelitian ini diketahui bahwa kemajuan persalinan kala I fase aktif pada kelompok intervensi (pelvic rocking exercise $)$ diperoleh nilai rata-rata $=240,67$ menit $(6$ jam) dengan nilai minimum 90 menit (1,5 jam) dan nilai maximum 360 menit (6 jam) sedangkan pada kelompok kontrol (non pelvic rocking exercise) diperoleh nilai rata-rata $=348,67$ menit $(5,8$ jam $)$ dengan nilai minimum 240 menit ( 4 jam) dan nilai maximum 450 menit (7,5 jam).

Hal ini sesuai dengan teori bahwa posisi upright dengan duduk diatas birthing ball atau disebut teknik pelvic rocking exercise dan berjalanjalan, berdiri, sama- sama dalam posisi tegak. Keduanya memberikan efek mempercepat proses persalinan. Namun, posisi duduk diatas bola dengan pelvic rocking lebih disukai karena ibu lebih rileks dan tidak mudah lelah.Dengan duduk ibu tetap dapat membantu penurunan kepala dengan gravitasi tetapi tidak lelah karena tidak membawa beban perut.Sehingga posisi ini membuat ibu lebih bertahan lama untuk dalam posisi upright (Sherwood, 2012).

C. Efektivitas pelvic rocking exercise menggunakan Birth ball terhadap kemajuan persalinan

Berdasarkan penelitian yang dilakukan oleh RR.Catur Leny Wulandari dan Sri Wahyuni (9) tentang Efektifitas Pelvic Rocking Exercise pada ibu bersalin kala I terhadap kemajuan persalinan dan lama persalinan dengan subjek penelitian adalah ibu bersalin kala I sejumlah 28 responden dan didapatkan bahwa ada hubungan antara Pelvick Rocking Exercise dengan lama kala I dengan p value $0,008 \quad(<0,05)$. Sehingga didapatkan penelitian ini sesuai dengan teori yang menyebutkan bahwa mobilisasi persalinan dengan 
Pelvick Rocking Exercise, yaitu duduk dengan perlahan mengayunkan dan menggoyangkan pinggul kedepan dan belakang, sisi kanan, sisi kiri, dan melingkar, akan bermanfaat untuk tekanan dari kepala bayi pada leher rahim tetap kostan ketika ibu bersalin diposisi tegak, sehingga dilatasi (pembukaan) servik dapat terjadi lebih cepat (Aprilia, 2011).

Sejalan dengan penelitian Diah Evawanna Anuhgera, Nikmah Jalilah Ritonga, Riris Sitorus, Juni Mariati Simarmata (9) tahun 2021 Hasil penelitian ini menunjukkan bahwa birth ball dengan teknik pelvic rocking dapat efektif mempercepat lama persalinan kala I fase aktif sebesar 52,61\% dibandingkan tanpa menggunakan birth ball dan diperkuat dengan nilai $\mathrm{p}=0.001$ yang menunjukkan ada pengaruh pemberian terapi birth ball dengan teknik pelvic rocking terhadap lama persalinan kala I fase aktif.

\section{KESIMPULAN}

Dari semua jurnal yang peneliti review dapat dipastikan bahwa kesemua jurnal tersebut mendapatkan hasil yang sama yaitu menyatakan bahwa dengan menggunakan teknik Pelvic Rocking Exercise dengan bantuan alat birthing ball dapat membuat waktu persalinan pada ibu bersalin menjadi lebih cepat dibanding dengan yang menggunakan teknik konvensional.

Peneliti mengemukakan dari 6 jurnal yang di review kesemua jurnal menerapkan pelvic rocking exercise menggunakan Birth ball terhadap ibu bersalin primigravida yang memasuki kala I fase aktif sampai dengan pembukaan lengkap dan semua jurnal tersebut mendapatkan hasil yang menyatakan bahwa penerapan teknik pelvic rocking exercise menggunakan Birth ball dapat memperpendek lama waktu persalinan kala I fase aktif pada ibu bersalin.

\section{DAFTAR PUSTAKA}

1. Kurniarum, Ari.2016. Asuhan Kebidanan Persalinan dan Bayi Baru Lahir. Jakarta: Kemenkes RI.

2. Depkes RI. 2014. Asuhan Persalinan Normal. Jakarta: JNPK-KR

3. Sofian, Amru. 2013. Sinopsis ObstetriJilid 1. Jakarta: EGC

4. Kemenkes RI. (2020). Profil Kesehatan Indonesia Tahun 2020. Jakarta: Balitbang. Kemenkes RI.

5. Aprilia. (2011). Gentlerkan Birth-Melahirkan Nyaman Tanpa Rasa Sakit. Grasindo.

6. Mathew, Albin, dkk. 2012. A Comparative Study on Effect of Ambulation and Birthing Ball on Maternal and Newborn Outcome among
Primigravida Mothers in Selected Hospital in Mangalore. Nitte University Journal of Health Science. 2(2)

7. Denney, A. ., \& R, T. (2013). How to write a iterature reviewe. Journal of Criminal Justice Education, 218-234.

8. Zed, M. (2004). Metode Penelitian Kepustakaan. Yayasan Pustaka Obor Indonesia

9. Wulandari, R. C. L., \& Wahyuni, S. (2019). Efektifitas Pelvic Rocking Exercise pada Ibu Bersalin Kala I Terhadap Kemajuan dan Lama Persalinan. Intan Husada. Jurnal Ilmu Keperawatan, 67- 77.

10. Anuhgera E D, Ritonga J N,Sitorus Riris, Simarmata M J (2021). Penerapan Birth Ball dengan tehnik Pelvic Rocking Terhadap Lama Persalinan Pada Kala I Fase Aktif. JKF. Jurnal Keperawatan dan Fisioterapi, 70-76.

11. Batubara, Ardiana Mahayani Eva, Al FaiqAgma Annisa. Pengaruh Pelaksanaan Pelvic Rocking Dengan Birth Ball Terhadap Kemajuan Persalinan Pada Ibu Bersalin Di Klinik Pratama Tanjung Deli Tua Tahun 2018.Colostrum Jurnal Kebidanan. Vol 1 No. 1 